\title{
Job Satisfaction and Evidence of Burnout Comparing Arab and Non-Arab Urologists with a Migration Background Working in German Hospitals
}

\author{
Matthias May ${ }^{1}$ Mohammad Shaar ${ }^{1}$ \\ ${ }^{1}$ Department of Urology, St. Elisabeth Hospital Straubing, Brothers of \\ Mercy Hospital, Straubing, Germany \\ Avicenna J Med 2021;11:196-199.
}

\author{
Address for correspondence Matthias May, MD, Department of \\ Urology, St. Elisabeth Hospital Straubing, Brothers of Mercy Hospital, \\ St. Elisabeth Street 23, 94315 Straubing, Germany \\ (e-mail: matthias.may@klinikum-straubing.de).
}

\author{
Abstract \\ Keywords \\ - urology \\ - immigration \\ - physicians \\ - emotional exhaustion \\ - depersonalization \\ - reduction in personal \\ accomplishment
}

Background In German hospitals, severe shortage of physicians can currently be partially compensated by hiring foreign physicians. Results on job satisfaction (JS) and physician burnout (PBO) in this important occupational group are currently not available.

Methods The cross-sectional "Assessment of their urological work environment by foreign clinicians in Germany (EUTAKD)" study was conducted in 2020 using a 101-item questionnaire among physicians working in German urological departments who were born in a country outside Germany and having non-German citizenship. This study compared JS and the occurrence of PBO between Arab (group A, $n=57$ ) and non-Arab (group B, $n=39$ ) participants.

Results Significant group differences with advantages for group B were analyzed in overall JS and also in other JS items. High scores in the PBO dimensions, that is, "emotional exhaustion" and "depersonalization," were shown by 27.9 and $51.5 \%$ of the study participants, respectively, although there were no group differences found ( $p=$ 0.972 and 0.237 , respectively).

Conclusion Prospective longitudinal studies of appropriate intervention measures aimed at increasing JS and decreasing PBO are needed.

\section{Introduction}

In German hospitals, the severe shortage of physicians can currently be compensated partially by hiring foreign physicians. The number of foreign physicians in Germany has increased from 16,818 in 2007 to 52,361 in $2019 .{ }^{1}$ Germany's urological departments also benefit from the increasing immigration of physicians in recent years to maintain its functionality. ${ }^{1}$ A successful integration of foreign colleagues always has professional, social, and linguistic components, although may be dissatisfactory in the private and professional environment, as well as burnout interfere overall with integration. ${ }^{2}$ Physician burnout (PBO) affects the wellbeing and also the safety of physicians and patients alike, however, it has not been sufficiently studied for urologists yet. ${ }^{3,4}$ In a recently published study of U.S. residents from a variety of specialties, the prevalence of $\mathrm{PBO}$ was the highest in the field of urology at $63.8 \%{ }^{5}$ Results on job satisfaction (JS) and PBO among physicians who immigrated to Germany are currently not available. published online

October 5, 2021
DOI https://doi.org/ $10.1055 / \mathrm{s}-0041-1735127$ ISSN 2231-0770.

\footnotetext{
C 2021. Syrian American Medical Society. All rights reserved. This is an open access article published by Thieme under the terms of the Creative Commons Attribution-NonDerivative-NonCommercial-License, permitting copying and reproduction so long as the original work is given appropriate credit. Contents may not be used for commercial purposes, or adapted, remixed, transformed or built upon. (https://creativecommons.org/ licenses/by-nc-nd/4.0/) Thieme Medical and Scientific Publishers Pvt. Ltd., A-12, 2nd Floor, Sector 2, Noida-201301 UP, India
} 


\section{Methods}

The study "Assessment of their urological work environment by foreign clinicians in Germany (EUTAKD)" was conducted using a 101-item questionnaire between August 1 and October 31, 2020, among physicians working in German urological departments who were born in a country outside Germany and having non-German citizenship (EUTAKD survey elaborated in -Supplementary Material S1; available online only). For this study, a positive vote was issued by the Ethics Committee of the University of Regensburg, Germany (ZE: 20-1808-101), and funding was provided by the Hans Neuffer Foundation.

The "Maslach Burnout Inventory (MBI)," as a robustvalidated instrument to quantify PBO, contains three dimensions: emotional exhaustion (EE), depersonalization (DP), and reduction in personal accomplishment (RPA). ${ }^{6,7}$ A sum score can be created by the responses in each dimension from which the burnout categories low, moderate, and high, respectively, are deduced. A high PBO risk is assigned to sum scores of $\geq 27, \geq 10$, and $\leq 31$ in the dimensions EE, DP, and RPA, respectively. ${ }^{3-7}$ The response options for recording JS covered the spectrum of a 5-point Likert's scale (an explanation in this regard is provided in -Table 1). The exact methodological conduct of the study and the composition of the whole study group in the different endpoints have been presented in previous publications. ${ }^{8,9}$

In this brief report, the difference between physicians from Arab (study group A) and non-Arab (study group B) countries regarding their JS, as well as PBO, was investigated. Here, differences in characteristics of the participants and JS between both study groups were tested using the Chi-square test and the nonparametric Mann-Whitney U-test, respectively; in addition, separate multivariate logistic regression models with backward elimination were used to examine the influence of the group variable on the three dimensions of PBO.

\section{Results}

A total of 96 foreign physicians' questionnaires could be evaluated of which 57 (59.4\%) belonged to study group A. In study group A, colleagues from Syria $(n=33,55.9 \%$ of study group A), Iraq ( $n=4,6.8 \%)$, Saudi Arabia ( $n=4,6.8 \%$ ), and Egypt ( $n=3,5.1 \%$ ) were the most common. Of the whole study group, $80.2 \%$ were $<40$ years of age ( $86 \%$ in group A vs. $71.8 \%$ in group $B, p=0.118), 90.6 \%$ were male $(98.2$ vs. $79.5 \%$, $p=0.003), 71.9 \%$ were married ( 77.2 vs. $64.1 \%, p=0.174)$,

Table 1 Selected items of participants' private and professional satisfaction compared between study groups, divided by country of origin: urologists from Arab countries (group A) versus urologists from non-Arab countries (group B)

\begin{tabular}{|l|l|l|l|l|}
\hline Satisfaction with & Whole study group $^{\mathbf{a}}$ & Group A $^{\text {a }}$ & Group B $^{\mathbf{a}}$ & $p^{\mathbf{b}}$ \\
\hline Time for family, friends, and leisure activities & $3(2-3)$ & $3(2-3)$ & $3(2-4)$ & 0.551 \\
\hline Work-life balance & $3(2-3)$ & $3(2-3)$ & $3(2-4)$ & 0.318 \\
\hline Quality of life in Germany & $4(4-4)$ & $4(3-4)$ & $4(4-5)$ & 0.007 \\
\hline Oral German language skills (in private life) & $4(3-4.75)$ & $4(3-4)$ & $4(4-5)$ & 0.036 \\
\hline Written German language skills (in private life) & $4(3-4)$ & $4(3-4)$ & $4(4-5)$ & 0.013 \\
\hline Overall job situation & $4(3-4)$ & $3(3-4)$ & $4(3-5)$ & 0.006 \\
\hline Work load & $3(3-3.75)$ & $3(2-3)$ & $3(2-4)$ & 0.247 \\
\hline Intellectual stimulation at work & $3(3-4)$ & $3(3-4)$ & $4(3-4)$ & 0.034 \\
\hline Stress level at work & $3(2-4)$ & $3(2-3)$ & $3(3-4)$ & 0.068 \\
\hline Career opportunities & $4(3-4)$ & $4(3-4)$ & $4(3-5)$ & 0.173 \\
\hline Work enjoyment & $4(3-4)$ & $3(3-4)$ & $4(3-5)$ & 0.073 \\
\hline Quality of the urological training in Germany & $3.5(3-4)$ & $3(2-4)$ & $4(3-4)$ & 0.007 \\
\hline Quality of the urological care in Germany & $4(4-5)$ & $4(4-4)$ & $4(4-5)$ & 0.082 \\
\hline Own surgical further development & $3(2-4)$ & $3(2-3)$ & $3(3-4)$ & 0.005 \\
\hline Own nonsurgical further development & $4(3-4)$ & $4(3-4)$ & $4(3-4)$ & 0.412 \\
\hline Own further training opportunities & $4(2.25-4)$ & $3(2-4)$ & $4(3-4)$ & 0.260 \\
\hline Income & $4(3-4)$ & $4(3-4)$ & $4(3-4)$ & 0.450 \\
\hline Oral German language skills (at work) & $4(4-5)$ & $4(4-5)$ & $4(4-5)$ & 0.459 \\
\hline Written German language skills (at work) & $4(4-5)$ & $4(3-4)$ & $4(4-5)$ & 0.056 \\
\hline Sum score of satisfaction with private and professional items (n= 39, see - Supplementary Material S1) & 0.002 \\
\hline
\end{tabular}

Note: The range of the value level comprised a 5-point Likert's scale (1: very dissatisfied, 2: rather dissatisfied, 3: partly satisfied and/or partly dissatisfied, 4: rather satisfied, and 5: very satisfied).

${ }^{a}$ The median value including the interquartile range (IQR) is shown in each case.

b In case of significantly different group comparison, the numbers of the more satisfied group were formated in italic. 
$54.3 \%$ had a permanent employment contract (52.1 vs. $57.6 \%$, $p=0.656)$, and $24.7 \%$ were employed as senior or chief physicians ( 20.8 vs. $30.3 \%, p=0.433$ ).

The differences between both study groups in JS are shown in -Table 1. There were significant group differences in the items "Quality of life in Germany" ( $p=0.007)$, "Overall job situation" ( $p=0.006)$, "Intellectual stimulation at work" ( $p=$ 0.034 ), "Quality of the urological training in Germany" ( $p=$ $0.007)$, “Own surgical further development" $(p=0.005)$, and "The total score" (consisting of 39 items, $p=0.002$ ) with greater satisfaction among the participants of study group B. Concerning oral and written knowledge of the German language, significant differences were present only in the private sector (orally: $p=0.036$, written: $p=0.013$ ) but not in the workspace (orally: $p=0.459$, written: $p=0.056 ;-$ Table 1 ).

High PBO scores in the EE, DP, and RPA dimensions were shown by $27.9,51.5$, and $73.5 \%$ of the study participants, respectively. According to the multivariate models, there was no independent influence of the group variable in the PBO dimensions EE and DP ( - Table 2). However, non-Arab compared with Arab study participants showed a relative decrease of $86.4 \%$ in high risk of RPA (odds ratio [OR] = $0.136, p=0.012$ ).

\section{Discussion}

The EUTAKD study is the first research on this topic and provides significant results, that can contribute to measures for better integration of this important professional group. High satisfaction in private and professional life also contributes to better resilience and additionally improves physicians' motivation to provide optimal patient care. ${ }^{7,10}$ However, satisfaction with a particular life situation always depends on prior personal experience. If, for example, urological training and the associated surgical personal responsibility are better in the country of origin than currently in Germany, this would result in dissatisfaction. Here it will be important for the "German Urological Association" and the urological clinics in Germany to use and continuously develop the existing professional expertise of colleagues with a migration background, in particular. In any case, identification with the specialty of urology has a very high degree, with only $8.4 \%$ of Arab colleagues and $15.1 \%$ of non-Arab colleagues intending to switch from urology to another specialty. ${ }^{9}$ Furthermore, only 4.2 and $3.0 \%$ of the colleagues, respectively, are intended to definitely leave Germany again. ${ }^{9}$

\section{Limitations}

Our EUTAKD study is limited by a sampling or selection bias and by the underlying cross-sectional design. For this reason, we see this pilot study more as descriptive and hypothesisgenerating study, so that it should be followed by more extensive additional studies on this topic. When interpreting the concrete results of the study, it should be noted that due to the methodological design of a SurveyMonkey, a response rate for the questionnaires cannot be specified as the total number of urological colleagues with a migration background in German hospitals is unknown. For this reason, statements on the representativeness of the study results unfortunately remain speculative. ${ }^{11,12}$

Table 2 Multivariate regression models ${ }^{\mathrm{a}}$ to test for an independent association of the group variable on high burnout in the dimensions of EE, DP, and RPA

\begin{tabular}{|c|c|c|c|}
\hline Study criteria & Odds ratio & $95 \% \mathrm{Cl}$ & $p$ \\
\hline \multicolumn{4}{|l|}{$\mathrm{EE}$ (sum score of $\mathrm{EE} \geq 27$ points) } \\
\hline Age groups (final model) & 0.549 & $0.236-1.273$ & 0.162 \\
\hline Groups B vs. A (excluded in the 3rd step) & 1.021 & $0.316-3.298$ & 0.972 \\
\hline \multicolumn{4}{|l|}{ DP (sum score of DP $\geq 10$ points) } \\
\hline Age groups (final model) & 0.186 & $0.059-0.588$ & 0.004 \\
\hline Nonmarried vs. married (final model) & 0.441 & $0.128-1.512$ & 0.193 \\
\hline Groups B versus A (final model) & 1.956 & $0.643-5.949$ & 0.237 \\
\hline \multicolumn{4}{|l|}{ RPA (sum score of RPA $\leq 31$ points) } \\
\hline SP/HP vs. Res/Con (final model) & 0.076 & $0.015-0.378$ & 0.002 \\
\hline Nonmarried vs. married (final model) & 0.134 & $0.028-0.641$ & 0.012 \\
\hline Groups B vs. A (final model) & 0.136 & $0.040-0.668$ & 0.012 \\
\hline
\end{tabular}

Abbreviations: $\mathrm{Cl}$, confidence interval; Con, consultant; DP, depersonalization/loss of empathy; EE, emotional exhaustion; Group A, urologists from Arabic countries; Group B, urologists from non-Arab countries; HD, head of department; Res, resident; RPA, reduction in personal accomplishment; $\mathrm{SP}$, senior physician.

a only the final step of the backward elimination is shown, where in addition to the group variable (group B vs. group A), five further criteria were always included in the first step: (1) age of the participant (six categories), (2) gender (male vs. female), (3) partnership (dichotomized into nonmarried vs. married), (4) employment contract (permanent vs. fixed term), and (5) position in the department (SP/HD vs. Res/Con). 


\section{Conclusion}

In conclusion, it can be deduced from our results that urologists with a migration background in German clinics show only average JS and exhibit an increased risk of PBO. Although the study group of urologists from Arab countries is of course a very heterogeneous cohort, our study for these colleagues now provides results for the first time on various criteria of JS and also on possible burnout problems due to working in German hospitals. According to the results of this pioneering study, JS was comparatively higher among urologists with a migration background from non-Arab countries, while there were no relevant differences in burnout rates between the two study groups. Prospective longitudinal studies investigating the preventive effect of improved integration measures on higher JS and lower PBO should follow.

\section{Disclosure}

A positive vote was given by the Ethics Committee of the University of Regensburg: ZE: 20-1808-101.

In accordance with the determinations of the Ethics Committee, informed consent was not obtained from study participants.

\section{Funding}

This work was supported by the Hans Neuffer Foundation.

Conflict of Interest

None declared.

\section{References}

1 Bundesäztekammer. Available at: www.bundesaerztekammer.de. Accessed April 29, 2021

2 Sabitova A, Sajun SZ, Nicholson S, Mosler F, Priebe S. Job morale of physicians in low-income and middle-income countries: a sys- tematic literature review of qualitative studies. BMJ Open 2019;9 (12):e028657

3 Sturm H, Rieger MA, Martus P et al; WorkSafeMed Consortium. Do perceived working conditions and patient safety culture correlate with objective workload and patient outcomes: a cross-sectional explorative study from a German university hospital. PLoS One 2019;14(01):e0209487

4 Hall LH, Johnson J, Heyhoe J, Watt I, Anderson K, O'Connor DB. Exploring the impact of primary care physician burnout and wellbeing on patient care: a focus group study. J Patient Saf 2020;16 (04):e278-e283

5 Dyrbye LN, Burke SE, Hardeman RR, et al. Association of clinical specialty with symptoms of burnout and career choice regret among US resident physicians. JAMA 2018;320(11):1114-1130

6 Rafferty JP, Lemkau JP, Purdy RR, Rudisill JR. Validity of the Maslach Burnout Inventory for family practice physicians. J Clin Psychol 1986;42(03):488-492

7 Howell TG, Mylod DE, Lee TH, Shanafelt T, Prissel P. Physician burnout, resilience, and patient experience in a community practice: correlations and the central role of activation. J Patient Exp 2020;7(06):1491-1500

8 May M, Shaar M, Gumz A, et al; Relationship between nonmedical reading and burnout as well as professional satisfaction among urologists with migrant background: results of the EUTAKD survey study conducted at German hospitals [in German]. Aktuelle Urol 2021(e-pub ahead of print). Doi: 10.1055/a1398-2197

9 Braun KP, Shaar M, Gumz A, et al. Job satisfaction and intentions to leave of foreign-national urologists working at German hospitals - Results of the cross-sectional EUTAKD study. Urol Int 2021. Doi: $10.1159 / 000518237$

10 McKinley N, McCain RS, Convie L, et al. Resilience, burnout and coping mechanisms in UK doctors: a cross-sectional study. BMJ Open 2020;10(01): 031765

11 May M. Satisfaction of foreign physicians in urological clinics in Germany. Uro-News24;. Doi: 10.1007/s00092-020-4183-9

12 EUTAKD-Studie evaluiert die berufliche und private Integration ausländischer Urologen. Available at: https://uroforum.de/eutakdstudie-evaluiert-die-berufliche-und-private-integration-auslaendischer-urologen/. Accessed April 29, 2021 